\title{
Differential Calorimetry on the Precipitation in Al-Cu-Cd Alloys
}

\author{
By Toshiya Hirata* and Shigeru Matsuo*
}

\begin{abstract}
An attempt has been made in order to investigate the effect of $\mathrm{Cd}$ atoms on the precipitation in $\mathrm{Al}-\mathrm{Cu}$ alloys by means of a differential calorimeter.

A heat evolution was found over a temperature range between $190^{\circ}$ and $280^{\circ} \mathrm{C}$ in the curve of power difference versus temperature of the quenched $\mathrm{Al}-\mathrm{Cu}-\mathrm{Cd}$ alloy and this heat evolution could be divided into two parts : the first of the two heat evolutions was attributed to the formation of the intermediate $\theta^{\prime}$ phase whose nucleation was stimulated by $\mathrm{Cd}$ atoms, and the second small heat evolution following the first one was due to the formation of the $\theta^{\prime}$ phase which was not related to $\mathrm{Cd}$ atoms.

The activation energies for the first and second heat evolutions were determined to be $0.6 \mathrm{eV}$ and $1.7 \mathrm{eV}$ respectively. The transformation $\theta^{\prime}-\theta$ in the quenched ternary alloy was delayed as compared with that in the quenched binary alloy. The effects of thermal histories of specimens, quenching temperature, $\mathrm{Cd}$ concentration and cold work were also examined.

(Received October 23, 1969)
\end{abstract}

\section{Introduction}

Precipitation processes of $\mathrm{Al}-\mathrm{Cu}$ alloys with ternary elements such as $\mathrm{Cd}$, In and $\mathrm{Sn}$ have been investigated by many workers ${ }^{(1) \sim(4)}$. It has generally been known that these elements reduce the rate of G.P. zones formation and stimulate the nucleation of the intermediate $\theta^{\prime}$ phase. The retardation of G.P. zones formation is associated with the decrease of the effective vacancy concentration for the diffusion of copper atoms by the interaction between vacancies and ternary elements ${ }^{(5)}$. The stimulation of the nucleation of the $\theta^{\prime}$ phase is considered to be due to the absorption of these elements at the interface between the $\theta^{\prime}$ phase and the matrix to lower the interfacial energy, thereby reducing the critical nucleus size for the precipitation of the $\theta^{\prime}$ phase ${ }^{(6)}$.

Silcock et al. ${ }^{(3)}$ have reported from their X-ray investigation that the sequence of precipitation in $\mathrm{Al}-\mathrm{Cu}$ alloys with small amounts of ternary elements such as $\mathrm{Cd}$, In and Sn can be written as follows, placing the less important structure in parentheses.

$$
\begin{aligned}
\text { G.P. } 1 & -(\text { G.P. } 2)-(R)+\theta^{\prime}+P-\theta^{\prime}+P \\
& +\mathrm{Cd}^{\prime}-\theta^{\prime}+\mathrm{Cd}^{\prime}-\theta+\mathrm{Cd}^{\prime}-\theta+\mathrm{Cd},
\end{aligned}
$$

where $R$ and $P$ are sets of weak additional diffraction effects which are produced at the beginning of the $\theta^{\prime}$ stage and $\mathrm{Cd}^{\prime}\left(\mathrm{In}^{\prime}, \mathrm{Sn}^{\prime}\right)$ are intermediate structures from the binary Al-Cd (In, Sn) alloys which occur as weak diffraction effects in the later $\theta^{\prime}$ stage ${ }^{(7)}$.

Recently, Homes and Noble ${ }^{(8)}$ have suggested from the resistivity measurements of $\mathrm{Al}-\mathrm{Cu}-\mathrm{Cd}$ alloys that $\mathrm{Cd}$ atom-

* National Research Institute for Metals, Tokyo, Japan.

(1) H. K. Hardy : J. Inst. Metals, 80 (1951 52), 483.

(2) H. K. Hardy : ibid, 82 (1953 54), 236.

(3) J. M. Silcock, T. J. Heall and H. K. Hardy : ibid, 84 (1955 56), 23.

(4) H. K. Hardy : ibid, 84 (1955 56), 429.

(5) H. Kimura and R. R. Hasiguti : Acta Met., 9 (1961), 1076.

(6) J.B. M. Nuyten : ibid, 18 (1967), 1765.

(7) J. M. Silcock : J. Inst. Metals, 84 (1955 56), 19.

(8) E. Holmes and B. Noble : J. Inst. Metals, 95 (1967), 106.
vacancy-Cu atom clusters are formed during aging at temperatures between $180^{\circ}$ and $240^{\circ} \mathrm{C}$ and that the $\theta^{\prime}$ phase may be nucleated by the coalesence of these mobile clusters enriched with vacancies.

A good deal of work is needed to clarify in more detail the mechanism by which the precipitation behaviour in $\mathrm{Al}-\mathrm{Cu}$ alloys is modified by the ternary elements.

In the present work, an attempt has been made in order to investigate the effect of $\mathrm{Cd}$ atoms on the precipitation in $\mathrm{Al}-\mathrm{Cu}$ alloys by means of a differential calorimeter. The effects of thermal histories of specimens, quenching temperature, $\mathrm{Cd}$ concentration and cold work were also examined.

\section{Experimental Procedures}

The alloys used in the present experiment were prepared from $99.99 \mathrm{wt} \% \mathrm{Al}, 99.99 \mathrm{wt} \% \mathrm{Cu}$ and 99.9 wt $\% \mathrm{Cd}$. They were melted in an alumina crucible and cast into a copper mould. The cast ingots were then forged and annealed at $500^{\circ} \mathrm{C}$ for 7 days to disperse the casting structures. The data of chemical analysis of the specimens are shown in the footnote**. The specimens for the differential calorimetric measurement were cylindrical, $20 \mathrm{~mm}$ in diameter and $20 \mathrm{~mm}$ in length (16 $\mathrm{g}$ in weight).

All the specimens were homogenized at $530^{\circ} \mathrm{C}$ for 1 hour in an electric furnace and quenched in iced water at $0^{\circ} \mathrm{C}$. The curves of power difference versus temperature were obtained using the differential calorimeter equipped with an automatic recorder. The curves were obtained during re-heating the specimens from room temperature to $520^{\circ} \mathrm{C}$ at the heating rate of $1{ }^{\circ} \mathrm{C} / \mathrm{min}$. All the measurement were carried out in a vacuum of $10^{-4} \mathrm{~mm} \mathrm{Hg}$.

\begin{tabular}{lrccc}
\hline ** No. of specimens & $\mathrm{Cu}$ & $\mathrm{Cd}$ & $\mathrm{Fe}$ & $\mathrm{Si}$ \\
No. 1 & 4.21 & 0.044 & 0.015 & 0.004 \\
No.2 & 4.24 & 0.093 & - & - \\
No. 3 & 4.33 & 0.19 & - & - \\
& & & & (wt\%)
\end{tabular}

1970 Vol. 11 


\section{Results}

\section{Effect of thermal histories}

Figure 1 shows the curves of power difference versus temperature ( $\Delta P$ curve) for the $\mathrm{Al}-\mathrm{Cu}-\mathrm{Cd}$ alloys (No. 2) quenched, air-cooled and furnace-cooled from $530^{\circ} \mathrm{C}$, respectively. The time required to set the specimens in the calorimeter after quenching was about 45 minutes. The $\Delta P$ curve of quenched $\mathrm{Al}-4.3 \mathrm{wt} \% \mathrm{Cu}$ alloy was also measured as shown in the figure.

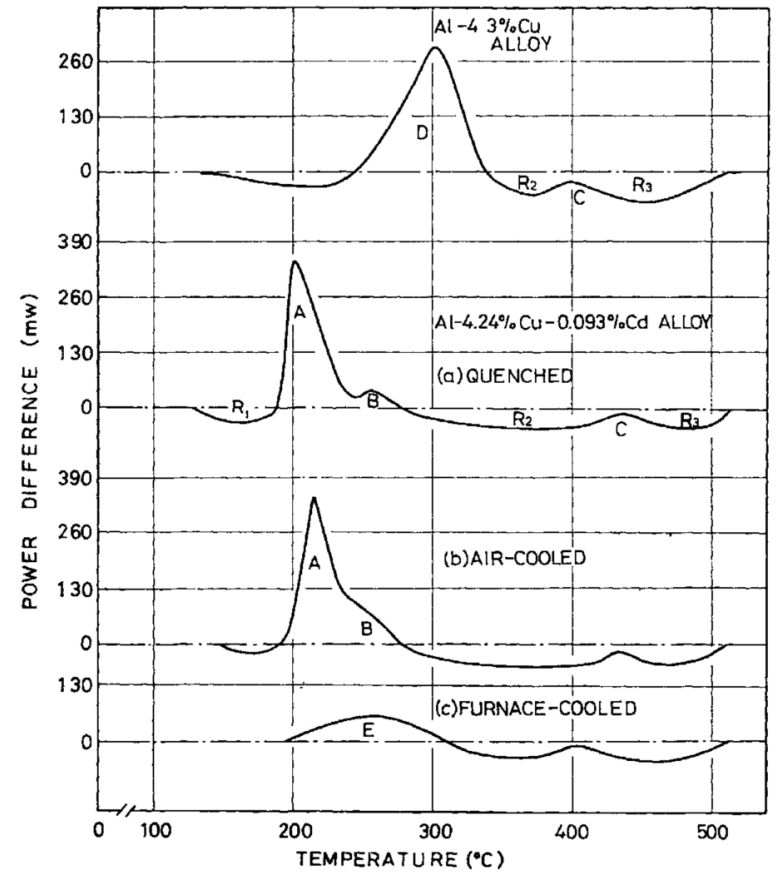

Fig. 1 Curves of power difference vs. temperature of the quenched $\mathrm{Al}-4.3 \% \mathrm{Cu}$ alloy and the quenched, air cooled and furnace cooled $\mathrm{Al}-4.24 \% \mathrm{Cu}-0.093 \% \mathrm{Cd}$ alloys from $530^{\circ} \mathrm{C}$, respectively.

In the $\Delta P$ curve of the quenched Al-Cu-Cd alloy, the first heat absorption $\left(R_{1}\right)$ represents the energy required to dissolve the G.P. zones formed at room temperature during the setting of the specimen after quenching. After the heat absorption $\left(R_{1}\right)$, a heat evolution is found over a temperature range between $190^{\circ}$ and $280^{\circ} \mathrm{C}$ and this heat evolution can be divided into two parts, $A$ and B. Similar results in the specific heat measurement of Al-4 wt \% Cu alloys with small amounts of Sn have been reported by Polmear et al. (9) Morinaga et al.(10) have also found a plateau between $240^{\circ}$ and $270^{\circ} \mathrm{C}$ in the specific curves for $\mathrm{Al}-4 \mathrm{wt} \% \mathrm{Cu}-0.1 \mathrm{wt} \% \mathrm{Sn}$ alloys.

The heat absorption $\left(R_{2}\right)$ is found following the heat evolutions $\mathrm{A}$ and $\mathrm{B}$. The heat absorption $\left(R_{2}\right)$ represents the energy required to dissolve the precipitates formed in the heat evolutions A and B. The small peak (C) corresponds with a heat evolution due to the transformation of the intermediate $\theta^{\prime}$ phase into the stable $\theta$ phase. The peak temperatures of the transformation $\theta^{\prime}-\theta$ in the quenched binary and ternary alloys were $400^{\circ} \mathrm{C}$ and $430^{\circ} \mathrm{C}$, respectively.

(9) I. J. Polmear and H. K. Hardy : J. Inst. Metals. 83 (1955), 393.

(10) T. Morinaga, M. Yamada and T. Takahashi : J. Japan Inst. Metals, $18(1954), 350$.
It should be noticed that the transformation $\theta^{\prime}-\theta$ in the quenched ternary alloy takes place at a temperature higher than that for the quenched binary alloy. Following the small peak $(\mathrm{C})$, the heat absorption $\left(\boldsymbol{R}_{3}\right)$ is found and this heat absorption represents the energy required to dissolve the $\theta$ phase into the matrix. The estimated amount of the heat evolution $(A+B), 4.66 \mathrm{cal} / \mathrm{g}$, is greater than the value, $4.07 \mathrm{cal} / \mathrm{g}$, for the heat evolution (D) in the quenched binary alloy. The value, 4.07 $\mathrm{cal} / \mathrm{g}$, is nearly equal to the value of $4.10 \sim 4.40 \mathrm{cal} / \mathrm{g}$ for the heat evolution due to the $\theta^{\prime}$ precipitation in $\mathrm{Al}-4 \mathrm{wt} \%$ $\mathrm{Cu}$ alloys as estimated by Swindells et al. ${ }^{(11)}$ and by Hirano et al. (12)

In the case of the air cooled specimen, the amount of the heat evolution was a little less than that in the quenched specimen and the separation between the two heat evolutions $A$ and $B$ became rather obscure, the amount of the heat evolution $(A+B)$ being $4.38 \mathrm{cal} / \mathrm{g}$.

On the other hand, in the case of the furnace cooled specimens, the first heat evolution (A) observed in the quenched and air cooled specimens disappeared and only a single heat evolution (E) was found over a temperature range between $200^{\circ}$ and $310^{\circ} \mathrm{C}$.

It is also clear that the heat evolution due to the transformation $\theta^{\prime}-\theta$ occurs at a lower temperature as compared with that in the quenched specimen and the peak temperature of the heat evolution is $402^{\circ} \mathrm{C}$, which is nearly equal to that of the heat evolution due to the transformation $\theta^{\prime}-\theta$ in the quenched $\mathrm{Al}-\mathrm{Cu}$ alloy.

The amount of energy release $(E)$ was $2.25 \mathrm{cal} / \mathrm{g}$.

\section{Effect of quenching temperature}

Figure 2 shows the $\Delta P$ curves of $\mathrm{Al}-\mathrm{Cu}-\mathrm{Cd}$ alloys



Fig. 2 Effect of quenching temperatures on the curves of power difference vs. temperature of $\mathrm{Al}-4.33 \%$ $\mathrm{Cu}-0.19 \% \mathrm{Cd}$ alloys.

(11) N. Swindells and C. Sykes : Proc. Roy. Soc., 168(1938), 237.

(12) K. Hirano and H. Iwasaki : Trans. JIM, 5 (1964), 162. 
(No. 3) quenched from $500^{\circ}, 520^{\circ}$ and $540^{\circ} \mathrm{C}$, respectively. The specimen was held at room temperature for 45 minutes before the setting of the specimen in the calorimeter after quenching.

The peak temperature shown by an arrow in Fig. 2 of the first heat evolution (A) shifted to a low temperature with increasing quenching temperature. The peak temperatures obtained were $220^{\circ}, 200^{\circ}$ and $197^{\circ} \mathrm{C}$ for the quenching temperatures of $500^{\circ}, 520^{\circ}$ and $540^{\circ} \mathrm{C}$, respectively.

\section{Effect of Cd concentration}

Figure 3 shows the $\Delta P$ curves of the quenched Al$\mathrm{Cu}-\mathrm{Cd}$ alloys with various $\mathrm{Cd}$ contents (No.1, No. 2 and No. 3). It is clear that the first heat evolution (A) becomes larger and the second heat evolution (B) has a tendency to become smaller with increasing $\mathrm{Cd}$ content. The amounts of the heat evolution $(A+B)$ in the specimens No. 1, No. 2 and No. 3 were $4.46 \mathrm{cal} / \mathrm{g}, 4.66 \mathrm{cal} / \mathrm{g}$ and $4.69 \mathrm{cal} / \mathrm{g}$, respectively. The peak temperatures of the first heat evolution observed in the specimens No. 1 and No. 2 were $220^{\circ}$ and $200^{\circ} \mathrm{C}$, respectively.

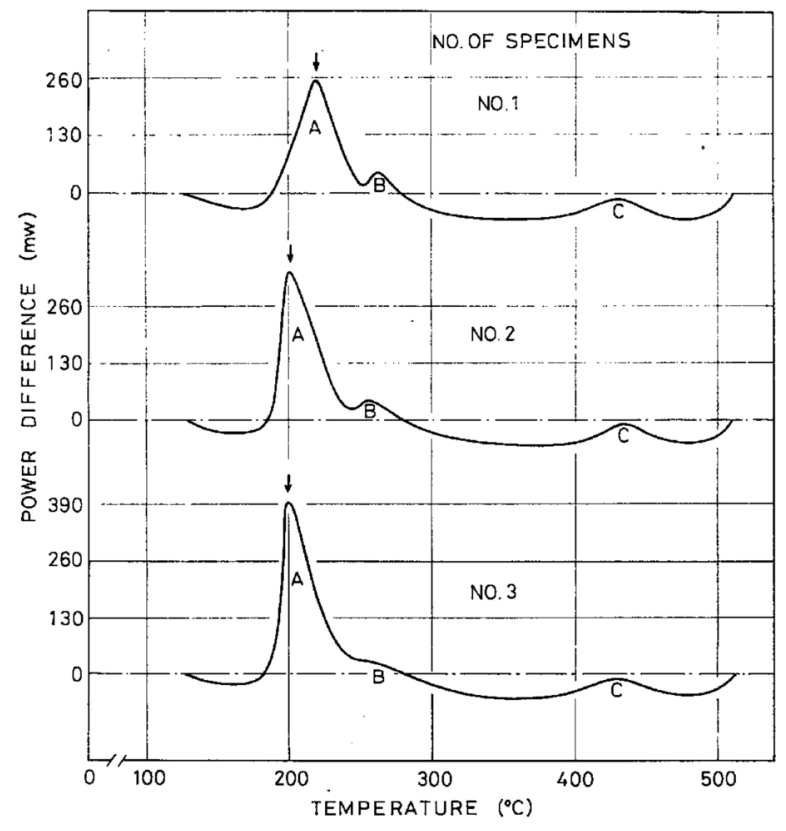

Fig. 3 Curves of power difference vs. temperature of the quenched $\mathrm{Al}-\mathrm{Cu}-\mathrm{Cd}$ alloys with various $\mathrm{Cd}$ contents.

It should be noticed that the peak temperature of the first heat evolution observed in the specimen No. 1 shifted to a low temperature with increasing Cd content. The peak temperature in the specimen No. 3 was identical to that of the first heat evolution observed in the specimen No. 2. The peak temperature of the heat evolution due to the transformation $\theta^{\prime}-\theta$ was not altered with the change in $\mathrm{Cd}$ content.

\section{Cold-worked specimens}

Figure 4 shows the $\Delta P$ curves of $\mathrm{Al}-4.3 \mathrm{wt} \% \mathrm{Cu}$ alloy and Al-Cu-Cd alloy (No. 2) subjected to a $20 \%$ reduction in area by a swaging after quenching. The $\Delta P$ curves of the quenched $\mathrm{Al}-\mathrm{Cu}$ and $\mathrm{Al}-\mathrm{Cu}-\mathrm{Cd}$ alloys are also shown in the figure for comparison.
In the $A P$ curve of the cold worked Al-Cu-Cd alloy, the second small heat evolution (B) could not be definitely separated from the first heat evolution (A) as in the quenched specimen and only a broad heat evolution $(F)$ was found over a temperature range between $170^{\circ}$ and $280^{\circ} \mathrm{C}$. The amount of the heat evolution was 4.82 $\mathrm{cal} / \mathrm{g}$. This value is a little larger than that for the heat evolution $(A+B)$ in the quenched specimen. The peak temperature of the heat evolution due to the transformation $\theta^{\prime}-\theta$ was $385^{\circ} \mathrm{C}$ which was lower than that in the quenched specimen.

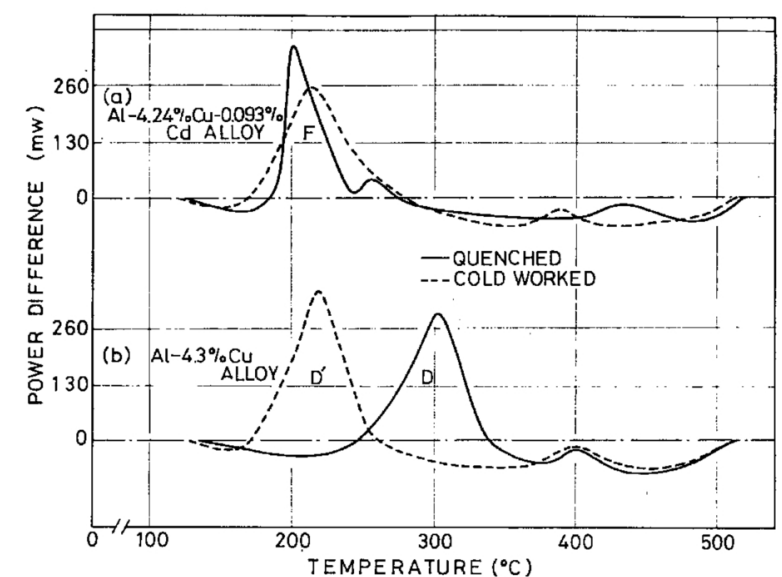

Fig. 4 Curves of power difference vs. temperature of Al$4.3 \% \mathrm{Cu}$ and $\mathrm{Al}-4.24 \% \mathrm{Cu}-0.093 \% \mathrm{Cd}$ alloys reduced $20 \%$ in area by a swaging after quenching.

In the $\Delta P$ curve of the cold worked $\mathrm{Al}-\mathrm{Cu}$ alloy, the peak temperature of the heat evolution $\left(D^{\prime}\right)$ was $215^{\circ} \mathrm{C}$ which was lower than that in the quenched specimen. The peak temperature of the heat evolution (D) in the quenched specimen was $300^{\circ} \mathrm{C}$.

The peak temperature of the heat evolution due to the transformation $\theta^{\prime}-\theta$ in the cold worked specimen was hardly altered as compared with that in the quenched specimen. The amount of the heat evolution $\left(D^{\prime}\right)$ was $4.65 \mathrm{cal} / \mathrm{g}$.

\section{Discussion}

\section{Activation energy for the heat evolution}

According to Nagasaki et al. ${ }^{(13)}$, it is possible to determine the activation energy for a heat evolution from the $\Delta P$ curve.

Assuming that the process is the first order reaction, the reaction rate can be generally written as follows:

$$
\mathrm{d} X / \mathrm{d} t=A e^{-E / k T}(1-X)
$$

where $A$ is a constant, $t$ the time, $E$ the activation energy for the reaction, $T$ the absolute temperature, $k$ the Boltzmann constant and $X$ is the fraction transformed at any given time. Now if taking $Q$ as the total amount of the heat evolution and $q$ as the amount of the heat evolved up to a temperature $T\left({ }^{\circ} \mathrm{K}\right), X$ is equal to the ratio of $q$ to $Q$. Therefore, eq. (1) can be rewritten as

(13) S. Nagasaki and A. Maesono : Metal Physics (in Japanese), 11 (1965), 182. 


$$
\mathrm{d} q / \mathrm{d} t=A e^{-E / k T}\langle Q-q) .
$$

Taking the logarithm,

$$
-\ln \mathrm{d} q / \mathrm{d} t+\ln (Q-q)=-\ln A+E / k T
$$

In Fig. $5,-\ln \mathrm{d} q / \mathrm{d} t+\ln (Q-q)$ is plotted against the reciprocal of the absolute temperatures for the two heat evolutions $\mathrm{A}$ and $\mathrm{B}$ observed in the quenched $\mathrm{Al}-\mathrm{Cu}-\mathrm{Cd}$ alloy (No. 2). In this case, the heat evolution (A) was separated from the heat evolution (B) by extrapolation because of their overlapping.

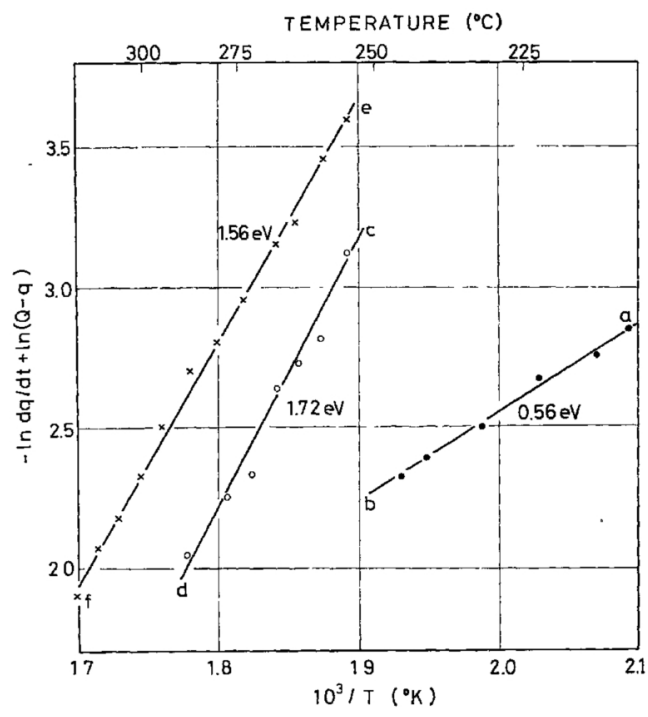

Fig. 5 Determination of the activation energies for the heat evolutions, A, B and D in the quenched $\mathrm{Al}-4.24 \%$ $\mathrm{Cu}-0.093 \% \mathrm{Cd}$ and $\mathrm{Al}-4.3 \% \mathrm{Cu}$ alloys, respectively.

The value of $\mathrm{d} q / \mathrm{d} t$ was approximately obtained by setting the value equal to $\Delta q / \Delta t$, where $\Delta q$ is the amount of the heat evolved at a temperature interval between $T$ and $T+\Delta T$ and $\Delta t$ is the time required to evolve $\Delta q$. The result for the heat evolution (D) observed in the quenched $\mathrm{Al}-\mathrm{Cu}$ alloy is also shown in the figure. The straight lines $a b, c d$ and ef correspond to the heat evolution, A, B and D, respectively. The activation energies for the heat evolutions $A, B$ and $D$ were determined from the slope of the lines to be $0.56 \mathrm{eV}, 1.72$ $\mathrm{eV}$ and $1.56 \mathrm{eV}$, respectively.

The activation energy, $E$, can be determined from the shift of the peak temperature of the heat evolution by using the following equation :

$$
E=k T_{1} T_{2} /\left(T_{1}-T_{2}\right) \times \ln \alpha_{1} T_{2}^{2} / \alpha_{2} T_{1}^{2}
$$

where $E$ is the activation energy for the reaction, $k$ the Boltzmann constant, $T_{1}$ the peak temperature of the heat evolution at a heating rate of $\alpha_{1}$ and $T_{2}$ is the peak temperature of the heat evolution at a heating rate of $\alpha_{2}$. This equation can be derived from equation (1) by setting $\mathrm{d}^{2} X / \mathrm{d} t^{2}$ equal to zero at the peak temperature of the heat evolution. In the present work, $T_{1}$ was $200^{\circ} \pm 2^{\circ} \mathrm{C}$ at a heating rate of $1^{\circ} \mathrm{C} / \mathrm{min}$ and $T_{2}$ was $220^{\circ} \pm 2^{\circ} \mathrm{C}$ at a heating rate of $2^{\circ} \mathrm{C} / \mathrm{min}$ for the heat evolution (A) in the quenched $\mathrm{Al}-\mathrm{Cu}-\mathrm{Cd}$ alloy (No. 2). Thus, the activation energy was determined to be $0.60 \mathrm{eV}$, in fairly good agreement with $0.56 \mathrm{eV}$ evaluated as above within the accuracy of error. The activation energy for the heat evolution (B) could not be determined from this method since the peak temperature for the heat evolution was not decided accurately.

The value of $0.56 \mathrm{eV}$ obtained for the heat evolution (A) is equal to the activation energy for the movement of a vacancy in aluminium. The value of $1.72 \mathrm{eV}$ for the heat evolution (B) approximates to the activation energy for the diffusion of copper atoms in aluminium although it is a little larger than the oft-quoted value. The value of $1.56 \mathrm{eV}$ obtained for the heat evolution (D) is nearly equal to the activation energy for the diffusion of copper atoms in aluminium and this value is close to the activation energy for the formation of the $\theta^{\prime}$ phase in $\mathrm{Al}-\mathrm{Cu}$ alloys ${ }^{(14)(15)}$.

It deserves particular attention that the activation energy for the heat evolution (A) is small at elevated temperatures above $190^{\circ} \mathrm{C}$. However, Homes and Noble ${ }^{(8)(16)}$ have reported that $\mathrm{Cd}$ atom-vacancy-Cu atom clusters are formed during aging at temperatures between $180^{\circ}$ and $240^{\circ} \mathrm{C}$ in $\mathrm{Al}-5.12 \mathrm{wt} \% \mathrm{Cu}-0.14 \mathrm{wt} \%$ $\mathrm{Cd}$ alloys and the activation energy for this process is determined to be $0.5 \mathrm{eV}$ from the dilatometric and resistivity measurements, and that the intermediate $\theta^{\prime}$ phase may be nucleated by the agglomeration of mobile $\mathrm{Cd}$ atom-vacancy-Cu atom clusters enriched with vacancies.

In the present work, it is shown that the peak temperature for the heat evolution (A) shifts to a low temperature with increasing quenching temperature and $\mathrm{Cd}$ content and the heat evolution $(\mathrm{A})$ becomes larger with increasing Cd content.

Therefore, it seems that the heat evolution (A) is associated with $\mathrm{Cd}$ atoms and quenched-in vacancies. Considering the low activation energy for the heat evolution which corresponds with the activation energy for the movement of a vacancy in aluminium, the heat evolution (A) is attributed to the formation of the intermediate $\theta^{\prime}$ phase whose nucleation is stimulated by $\mathrm{Cd}$ atoms.

The $\theta^{\prime}$ phase may be nucleated by the coalesence of $\mathrm{Cd}$ atom-vacancy-Cu atom clusters as proposed by Noble and it is considered that these clusters are formed during heating. It has also been reported by Noble that the nucleation of the $\theta^{\prime}$ phase is not affected by $\mathrm{Cd}$ atoms above the aging temperature of $240^{\circ} \mathrm{C}$ because the removal of Cd atoms from the interface between the $\theta^{\prime}$ phase and the matrix as the $\mathrm{Cd}^{\prime}$ precipitate occurs above this temperature.

In the present work, the second heat evolution (B) in the quenched $\mathrm{Al}-\mathrm{Cu}-\mathrm{Cd}$ alloy begins to occur at $240^{\circ} \mathrm{C}$. However, it is shown from the following reasons that this heat evolution is not due to the $\mathrm{Cd}^{\prime}$ precipitation. The activation energy for the heat evolution (B) was determined to be $1.72 \mathrm{eV}$, which is close to the activation energy for the diffusion of copper atoms in aluminium and is different from the value of $0.95 \mathrm{eV}$ for the diffusion of $\mathrm{Cd}$ atoms in aluminium. In addition, the heat

(14) G. Borelius, L. E. Lassen and H. Selberg : Arkiv für Fysik, 2 (1950), 15.

(15) G. Borelius, L.E. Lassen and H.Selberg : ibid, 11(1956),137.

(16) B. Noble : Acta Met., 16 (1968), 398. 
evolution (B) has a tendency to become smaller with increasing $\mathrm{Cd}$ content.

It is considered therefore that the heat evolution $(B)$ is due to the formation of the $\theta^{\prime}$ phase which is not related to $\mathrm{Cd}$ atoms. It can occur since the degree of supersaturation of copper atoms is retained in the matrix even after the formation of the $\theta^{\prime}$ phase related to $\mathrm{Cd}$ atoms.

\section{Retardation of the transformation $\theta^{\prime}-\theta$}

It is generally shown that the transformation $\theta^{\prime}-\theta$ in Al-Cu alloys occurs by the dissolution of the intermediate $\theta^{\prime}$ phase and the formation of the stable $\theta$ phase, and the new phase is usually nucleated in the previous location of the old phase (17)(18). Accordingly, it is apparent that the growth of the $\theta$ phase depends on the resolution of the $\theta^{\prime}$ phase.

In the present work, it is shown that the transformation $\theta^{\prime}-\theta$ in the quenched Al-Cu-Cd alloy is delayed as compared with that in the quenched Al-Cu alloy. It seems that this is associated with the increase in thermal stability of the $\theta^{\prime}$ phase in the quenched ternary alloy by the absorption of $\mathrm{Cd}$ atoms at the interface between the $\theta^{\prime}$ phase and the matrix.

For the reason described above, dissolution of the $\theta^{\prime}$ phase in the quenched ternary alloy is more difficult than that in the quenched binary alloy. In the $\Delta P$ curve, this is shown by the ratio of the amount of the heat absorption due to the dissolution of the $\theta^{\prime}$ phase to the amount of the heat evolution due to the formation of the $\theta^{\prime}$ phase.

The ratio of the amount of the heat absorption $\left(R_{2}\right)$ to the amount of the heat evolution $(A+B)$ in the quenched ternary alloy is larger than that of the amount of the heat absorption $\left(R_{2}\right)$ to the amount of the heat evolution (D) in the quenched binary alloy. This suggests that the formation of the $\theta$ phase depends on the dissolution of the $\theta^{\prime}$ phase and that dissolution of the $\theta^{\prime}$ phase in the quenched ternary alloy is more difficult than that in the quenched binary alloy, thus leading to the retardation of the transformation $\theta^{\prime}-\theta$ in the quenched $\mathrm{Al}-\mathrm{Cu}-\mathrm{Cd}$ alloy.

In the furnace cooled Al-Cu-Cd alloy, the peak temperature of the heat evolution due to the transformation $\theta^{\prime}-\theta$ approaches that in the quenched $\mathrm{Al}-\mathrm{Cu}$ alloy, because $\mathrm{Cd}$ atoms are removed from the mrtrix as $\mathrm{Cd}^{\prime}$ and $\mathrm{Cd}$ precipitates during furnace cooling and consequently the effect of $\mathrm{Cd}$ atoms on the thermal stability of the $\theta^{\prime}$ phase is diminished.

(17) M. v. Heimendal and G. Wasserman : Z. Metallk., 53 (1962), 275.

(18) M. v. Heimendal and G. Wasserman : ibid, 54 (1963), 385.
In the cold worked $\mathrm{Al}-\mathrm{Cu}-\mathrm{Cd}$ alloy, the peak temperature of the heat evolution due to the transformation $\theta^{\prime}-\theta$ was $385^{\circ} \mathrm{C}$ which was lower than that in the quenched specimen. This seems to be associated with the reduction of the availability of Cd atoms due to their absorption along the dislocations introduced by a cold work, as pointed out by Hardy et al. (19)

The above-mentioned reduction of the availability of $\mathrm{Cd}$ atoms is reflected in that the separation between the heat evolution (A) and (B) is difficult and the two heat evolutions are replaced by a broad heat evolution over a temperature range between $170^{\circ}$ and $280^{\circ} \mathrm{C}$ in the $\Delta P$ curve of the cold worked specimen.

\section{Conclusions}

The results on the precipitation in $\mathrm{Al}-\mathrm{Cu}-\mathrm{Cd}$ alloys obtained by a differential calorimeter are summarized as follows. A heat evolution was found over a temperature range between $190^{\circ}$ and $280^{\circ} \mathrm{C}$ in the curve of power difference versus temperature of the quenched $\mathrm{Al}-\mathrm{Cu}-\mathrm{Cd}$ alloy and this heat evolution could be divided into two parts.

The first of the two heat evolutions was attributed to the formation of the intermediate $\theta^{\prime}$ phase whose nucleation was stimulated by $\mathrm{Cd}$ atoms. The second small heat evolution following the first heat evolution was due to the formation of the $\theta^{\prime}$ phase which was not related to Cd atoms.

The activation energies for the first and second heat evolution were determined to be $0.6 \mathrm{eV}$ and $1.7 \mathrm{eV}$, respectively. The value of $0.6 \mathrm{eV}$ was equal to the activation energy for the movement of a vacancy in aluminium and the value of $1.7 \mathrm{eV}$ was close to the activation energy for the diffusion of copper atoms in aluminium.

The transformation $\theta^{\prime}-\theta$ in the quenched ternary alloy was delayed as compared with that in the quenched binary alloy. It is shown that the retardation of the transformation $\theta^{\prime}-\theta$ in the quenched ternary alloy occurs by the increase of the thermal stability of the $\theta^{\prime}$ phase due to the absorption of $\mathrm{Cd}$ atoms at the interface between the $\theta^{\prime}$ phase and the matrix.

\section{Acknowledgment}

The authors wish to thank Dr. R. Watanabe and Mr. K. Saito for their useful discussions and to Dr. H. Kimura for his continuous encouragement throughout the present work.

(19) H. K. Hardy : J. Inst. Metals, 83 (1954 55), 337. 